\title{
Moving from General Knowledge to Specific Knowledge in a Democratic Culture: A Case Study Approach
}

\author{
Avhurengwi Samson Mabade, Neziwe Lucia Mapangwana \\ Walter Sisulu University, Eastern Cape Province, Nelson Mandel Drive, Mthatha, South Africa \\ Email: amabande@wsu.ac.za
}

How to cite this paper: Mabade, A. S., \& Mapangwana, N. L. (2022). Moving from General Knowledge to Specific Knowledge in a Democratic Culture: A Case Study Approach. Open Journal of Social Sciences, 10, 298-313.

https://doi.org/10.4236/jss.2022.102022

Received: January 11, 2022

Accepted: February 22, 2022

Published: February 25, 2022

Copyright $\odot 2022$ by author(s) and Scientific Research Publishing Inc. This work is licensed under the Creative Commons Attribution International License (CC BY 4.0).

http://creativecommons.org/licenses/by/4.0/ (c) (i) Open Access

\begin{abstract}
The focus of this article is on the enhancement or amplification of specific knowledge to meet and respond to challenges in all myriad spheres of leadership in a democratic culture more especially principal of schools. Prior to democratic culture, general knowledge seemed to be predominant in all spheres of life. Moving from general knowledge to specific knowledge is a development that improves competence that can presumably strengthen and sustain a responsibly coherent profession and leadership in a democratic culture. The majority of people appeared to be on the level of general knowledge and they should not remain on this level of general knowledge. In a democratic culture, everyone has the right to know hence knowledge is the creation of human mind. Specific knowledge development is not a simplistic issue. This needs critical thinkers that quickly identify assumptions and challenge them. Due to general knowledge, people would try to reinvent a wheel in a time wasting fashion. General knowledge develops and promotes naïve argument in any environment more especially in a work environment hence specific knowledge develops and promotes intellectual argument which enhances improvement of attitude, behaviour and mindset that ultimately improve performance. Although the literature about knowledge development is abundant, there appear a few literatures about the shifting from general knowledge to specific knowledge. The researchers adopted a case study approach for the description and explanation of the problem. The researchers identified ten principals of schools from the same circuit area and conducted interviews to find out how they respond to certain problems. The purpose was to find out if they use general knowledge or specific knowledge to respond to their challenges. Their responses were presented as an inductive research.
\end{abstract}




\section{Keywords}

General Knowledge, Specific Knowledge and Democratic Culture

\section{Introduction and Motivation to the Study}

Since the advent of Democracy, people have enormous challenges at their work environments some of which they think they are insurmountable hence it is a question of specific knowledge to respond and mitigate any challenge. Clearheaded and critical thinking outlook should be qualities of leadership and community members in a democratic culture. Some appear to use general knowledge to respond to any challenge that happens to arise at work. One cannot be trained for a specific knowledge. Specific knowledge is found much more by pursuing your innate talents, your genuine curiosity and your passion. Therefore, knowledge transformation is imperative in a democratic culture. According to Waschenfelder (2019), specific knowledge is at the edge knowledge. It is a stuff that is just being figured out or really hard to figure out and tends to be technical and creative. It is on the bleeding of technology, on the bleeding edge of art and on the bleeding edge of communication. Most of the successful people got to be where they are by making things up as they go along and building specific knowledge one block at a time. One has to learn along the way and one learns by asking good questions, creating, failing, iterating and trying again. You learn specific knowledge by experiment. For this study, specific knowledge can be acquired through continuing professional education and research to learn more about the area of your interest. This triggers critical thinking and creativity. Unless you learn and ask other people, you would reckon on general knowledge only. The specific knowledge would help you to understand the phenomenology of your subordinates better. Specific knowledge strengthens and sustains strategic leadership which is significant towards the achievement of the objective of any organization.

General knowledge covers all knowledge available for related activities but not the specific one. It includes knowledge about which specific factors are important for understanding and managing the risk related to the specific installation or operation of interest. The specific knowledge covers knowledge concerning the specific installation or activity alone (Aven and Kristensen, 2019). For this study, specific knowledge should be implemented to solve a specific problem at a work environment. One should have a specific knowledge about a specific problem to avoid generalization which would result naïve argument at work. Ongoing default is morally unacceptable as the aftermath of general knowledge more especially in a democratic culture. Although human activity is precarious, specific knowledge can contribute towards minimizing the problem. Some would remain unequivocal due to general knowledge. Specific knowledge could promote forward thinking capabilities. Knowledge continually changes, new con- 
structs permit new perspectives and subsequent knowledge claims. Specific knowledge helps to create or establish niche at workplaces.

General knowledge may also impede understanding of new information. In order to understand such a negative influence, we must distinguish between quantity and the quality of such knowledge. A person's general knowledge may include fragmentary knowledge or even mistaken terms or concepts which can retard reading comprehension and cause the reader to construct an erroneous meaning (Kozminsky, 2001). General knowledge is easy to get. A person gets general knowledge from daily activities without exerting any extra effort. General knowledge is knowledge of many different things as opposed to detailed knowledge of a particular topic or subject. Sometimes is not good to be an expert in certain thing yet you do not have knowledge of things around you. There is goldmine of information that could help you to increase your general knowledge such as Television and Radio. However general knowledge is part of life which should be improved to specific knowledge.

The role of general knowledge as a component of intelligence and a good measure of it, remains in dispute or a bone of contention. The relationship between general knowledge and intelligence has been considered in other educational settings (Furnham \& Premuzic, 2006). Although general knowledge is the basic knowledge, it should be transformed into specific knowledge to avoid naive argument more especially in the purview of your work environment. Specific knowledge could help a person to make such remarkable contributions and considerations at any organization. This also promotes the development of a profound knowledge subservient to work related problems.

\section{Literature Review}

The literature review assisted the researchers to familiarise themselves with the conversation of their interest. Problem-solving is a skill that needs to be developed through specific knowledge. This also involves other skills such as communication, analysis, decision-making and dependability skills. Therefore, specific knowledge is more significant in problem-solving process than general knowledge. In most instances, people engage with naïve arguments due to general knowledge. However problem-solving skill can be improved by acquiring specific knowledge (Indeed Editorial Team, 2020).

Hrdy (2019), employers are encouraged to communicate trade secrets to employees, but this information loses protection if it becomes part of those employees' unprotected general knowledge, skills and experience. General knowledge, skills training and experience serve as sort of loose shorthand for the corpus of information every employee may take from job to job. General knowledge, skills and experience serve as a crucial limitation on the ability to use trade secret law to stop departures. Trade secret law does not protect general knowledge, skills and experience that an employee acquires during the course of employment. Therefore, general knowledge could assist in certain instances but 
should not be predominant in this democratic culture where everybody has the right to know. Leadership or employer should not be proselytizing ideologue leaders.

In the democratic culture, transformational leadership could be a most appropriate style of leadership. The transformational leadership includes the transactional style which was adopted in schools and colleges in Bangladesh. There is a strong relationship between transformational style and motivation of teachers. It would be important for the new generation of school leadership more especially school principals to fully understand transformational leadership. Leadership of a principal is the most significant contributing factor that influences school effectiveness (Hossain \& Mozumder, 2019).

In both problem-solving, decision making and transformational style of leadership, quality results are the expectations of the day. It is however, imperative to define the problem so that you can make decision about that problem hence general knowledge would force to get the results without understanding of the problem. The propensity of the leadership should be more esoteric. A clear understanding of assumptions made when engaging in the process is important. One can only identify and challenge assumptions if one is a critical thinker. One should gather information as much as one can understand the problem so as to bring amicable solution to the problem. Democratic culture has its own problems which need transformation obligation for autonomous reform. A leader should have a complex structure of attributes needed for competent performance.

\section{Research Design and Methodology}

The researchers adopted a Case Study Approach within a Critical Paradigm. A Critical Paradigm aims towards the empowerment of the respondents and focuses on the ways to change the situation. A Case study is qualitative in nature that is a systematic study of phenomenon which aims towards a description and explanation of a phenomenon. The researchers selected ten school principals under the same Circuit office's jurisdiction. The principals were randomly selected from the same Circuit area of management to find out their experiences in relation to responding to the challenges at their work environment. The respondents included principals of Primary and Secondary Schools. Although they were selected randomly, the sample included both female and male principals. The purpose of selecting respondents from the same area of school management was to find out if the work environment is predominated by General Knowledge or Specific Knowledge. Another purpose was to find out if schools within a fastidious area of management experience the same challenges. The respondents were interviewed at their respective working environment at their convenient time. The same questions were used for the interviews of all respondents. That helped in the validity and reliability of the measuring instruments. The purpose of using the same questions was to find their experiences on the same interview 
questions to confirm General Knowledge or Specific Knowledge. Their responses were recorded in a reflective diary and also audio-recorded and then transcribed by the researchers. The responses to the interview questions were presented as an inductive research report. The findings were analysed using data metrics and then interpreted.

\section{Results}

\section{The individuals' responses to interview questions}

Their responses were recorded and then transcribed by the researchers. The respondents used their experiences to respond to the interview questions. The purpose of the interview questions was to find out if the respondents use General Knowledge or Specific Knowledge in their respective work environment to meet or to deal with challenges as leadership of the institutions. The respondents used their daily experiences to respond to the interview questions. The aim of the research was to encourage the readers to use specific knowledge instead of general knowledge in their work environment to meet or address any challenge.

\section{How do you ensure quality teaching in your school?}

The first respondent indicated that the School Management Team is responsible for quality teaching in a school by providing necessary support to members of staff. It is imperative for each school to cultivate culture of learning and teaching. The respondent further showed that training of teachers more especially with regard to technology can also ensure quality teaching. School support teams such as School Governing Body could also add towards ensuring quality teaching. By and large teacher coaching is significant. The second respondent reported that quality monitoring by the School Management Team can ensure quality teaching in each school. The lesson plan should be checked in line with the teaching policy. There should be a clear teaching and learning policy that indicates monitoring of learners' work as well as curriculum coverage. The teaching policy includes both educators and learners class attendance. The respondent again indicated that his/her responsibility is to implement the policy. The third respondent showed that teacher's preparation should be checked regularly as well as regular class attendance. There should be rigorous discipline in all class for quality teaching and learning. The fourth respondent pointed out that educators should prepare their lessons thoroughly and avoided getting in the class unprepared. Curriculum coverage should be monitored time and again to ensure that subject content is treated and completed before half yearly examinations. This will ensure that there will be enough time for revision and to address individual learner's needs with easy. The respondent further indicated that quality assessment including classwork and tests help to ensure quality teaching. Both educators and learners should be supported in their endeavors. There should be a clear policy on teaching and learning which helps the leadership to ensure quality teaching. The fifth respondent indicated that leadership must make an assessment of the whole school to determine the strength and weakness of all 
human resources. Educators should make their own assessment so that they can sample and identify areas of support according to their abilities. A factually teaching plan should be developed based on the various abilities of learners and educators. There should be teaching plan, assessment plan, monitoring plan and support plans which should be implemented to improve quality of teaching in a school. The sixth respondent pointed out that monthly progress reports could assist to ensure quality teaching in schools which help to update parents about the performance of both teachers and learners. Learner support materials contribute towards ensuring quality teaching and learning. Therefore, it is the Department's obligation to supply all schools with learning materials to support quality teaching in each school.

The seventh respondent indicated that quality teaching is ensured by good communication skills with educators by the leadership. In addition, adhering to teaching standard methods recommended by the Department of Basic Education and Training. Constant self-evaluation of a school can contribute towards quality teaching. The eighth respondent showed that quality teaching can be ensure by implementing all the relevant teaching policies such as Curriculum Policy and Finance Policy. The relevant documents including assessment and monitoring tool documents should be mastered by the leadership to ensure quality teaching. The effective implementation of general timetable adds towards effective teaching in a school. The ninth respondent indicated that organized School Management Team could contribute much towards ensuring quality teaching. This should assist in the moderation of all assessment tasks to ensure quality including pre-moderation and post-moderation. The establishment of School Improvement Plan which can be implemented can also have magnificent contribution towards quality teaching. The tenth respondent pointed out that quality teaching can be ensured by class visits by the leadership to find out if educators are doing their best to improve the quality of teaching and learning.

The responses to the interview question indicated that the respondents are moving from general knowledge to specific knowledge because whatever they do to ensure quality teaching, they are grounded by the School Policy although the implementation thereof is not simplistic. They do not rely on General knowledge to ensure the quality of teaching in their respective schools. Teaching and learning Policies are included in responding to the interview question. It is crystal clear that the respondents have moved from general knowledge to specific knowledge.

\section{How do you handle a case of corporal punishment by an educator?}

The first respondent reported that an educator who inflicts corporal punishment should face the consequences because it is abolished by the South African School Act. This does not need any special treatment. The second respondent indicated that corporal punishment is no longer allowed in schools so teachers have to devise ways in which they can keep their classroom environment manageable. There are ways in which learners can be punished without using corporal 
punishment. This problem should be treated based on the School Policy. This is a misconduct by the teacher which needs procedures including writing of reports by the teacher who inflicted corporal punishment. The School Governing Body should also receive a full report as well as the Circuit office. The principal alone cannot resolve this problem. The third respondent showed that the educator should be called to the office so that the principal could get a full story. The teacher is obviously guilty in this regard because it is a misconduct by the educator. The teacher should be reminded about the Constitution of South Africa including South African School Act (SASA). The educator should be given verbal warning. The parents of the learner should be informed about the incidence. The fourth respondent pointed out that no person has to administer corporal punishment in a school. Therefore, any educator who contravenes this, is guilty of an offence and liable to a sentence which could be equal to an assault. The fifth respondent indicated that this is a case to be reported to the police station by the victim. Both the educator and learners will have to come to the office for explanation. The educator is allowed to plead. Depending on the extent or seriousness of the offence, a process of reconciliation can be allowed to take place. Sometimes it might be necessary to call a learner's parent or guardian. A final written warning is issued to the educator. The sixth respondent showed that it a crime which should be done with by South African School Act. The complainant should provide evidence to the principal who should report this to the directorate. The School Governing Body (SGB) and the Circuit management should be informed for advice. The decision to charge the educator should be taken by the District office. The seventh respondent indicated that the principal will have to find out how it happened. The learner will have to asked questions to find out if the learner could forgive an educator. The educator will have to be reprimanded for such behaviour. The eighth respondent pointed out that the educator should be called in the office to explain the whole incidence. The secretary of the School Management Team records the minutes of the meeting. Again the educator should be reminded that corporal punishment is abolished. Therefore, no one is allowed to apply corporal punishment under any circumstance. The ninth respondent indicated that this problem should be treated in consultation with both parents and Circuit office. If both parties agreed to an amicable solution, the case can be closed. If one of these parties is not satisfied, the educator can be reminded to get a legal representative because it is abolished. It is not easy close this case of corporal punishment.

The responses to the interview question indicated that the respondents are abreast of the South African School Act and the Constitution of the country that contribute significantly to their Specific Knowledge in addressing problem of this nature more especially in this democratic culture. The respondents pointed out clearly that corporal punishment is abolished, therefore, the principal solely cannot settle this case of corporal punishment. They are aware that General Knowledge should not be applied in this regard, but instead Specific Knowledge 
that is amplified by School Policy, South African School Act and the Constitution. The knowledge that one can apply should be grounded by the School Policies.

\section{How do you handle a case of educator-learner's affairs?}

The first respondent pointed out that educators are parents of learners in a school. Therefore, they have to treat them equally. All principals are expected to include this motion in each staff meeting. The second respondent indicated that this case should be treated in line with code of conduct for educators and learners as well as the Departmental Discipline Policy. An educator should write a letter based on the allegation made on him. A report should be written to SGB of the allegation about the educator. The principal and the SGB are all responsible for this problem. The third respondent showed that he would call the educator to discuss the allegation. Verbal warning should be given to the educator. The educator will be told the danger of have affairs with learners. If the educator continues, second verbal warning should be given. The fourth respondent indicated that such a case should be dealt with by all stakeholders including SGB and SMT. The stakeholders should get stories from both parties, that is educator and the learner. These stakeholders compile a report to the Circuit Manager. The parent of the learner will also be involved in resolving the case. The fifth respondent pointed out that according to the Employment of Educators' Act, educators are not allowed to have intimate relationship with learners. If this misconduct takes place with evidence, the sanction is a guaranteed dismissal and possible arrest. The sixth respondent indicated that if a parent could bring this to the school, such a parent should be advised to report this case to the nearest police station because no educator is allowed to have affair with a learner in a particular school. The seventh respondent indicated that this is a criminal offence which needs strong evidence from the learner. The story should be well recorded with all evidence before could take it further to the Circuit office. This case cannot be resolved by the principal alone. The eighth respondent showed that a redefined procedure for resolving internal issues should be taken into consideration. The principal should involve SBG and School Development Committee to resolve this issue. The ninth respondent pointed out that the educator should be call in the office with SMT. The educator should write a report on the allegation made about him. The SMT should also keep a record during the meeting. The SMT should also get story from the learner herself. This will depend on the seriousness of the offence to resolve the case. The tenth respondent indicated that the principal cannot solve this problem with no reference to SASA. The School Policy should also be taken into consideration when resolving this issue. The principal alone cannot resolve this issue without School Governing Body and the Circuit Manger.

The responses to the interview question showed that the respondents are aware that in this Democratic culture, General Knowledge cannot be used to settle or resolve any problem more especially educator-learner affairs. They further 
proved to be abreast of the South African School Act and Educators' Employment Act. They rely on Specific Knowledge from the School Policy to address the problem of educator-learner affairs although the implementation part is not simplistic. They believed that principal alone cannot resolve problem of this magnitude hence there are levels of management that should also have contributions and considerations towards the resolution to the problem. To avoid scathing report by the principal, all the records should up to date and safe.

\section{How do you deal with teenage pregnancy in your school?}

The first respondent indicated that this problem is dealt with by enforcing teenage pregnancy programme. In addition, positive youth development should be promoted in a school. The second respondent pointed out that the school liaise with the parent of the pregnant teenage to discuss the way forward. The learner's right is protected from any form of discrimination. The school ensures the rights to equality, dignity, education and the right of the child who fell pregnant. The principal keeps record of learners who fell pregnant and report this to the Department of Basic Education and Training. The third respondent sowed that the Constitution of the country promotes the rights of all people including learners. Therefore, the learner cannot be expelled from school because of pregnancy. Once the learner falls pregnant, the SGB and learner's parent should agree on the protection and safety of the learner. The parent is responsible for any emergency needed by the learner. The fourth respondent indicated that the principal's responsibility is to communicate with the parents and the Department of Basic Education and Training on the development of the learner. The principal should keep his record up to date for his protection. The fifth respondent indicated that the school can only educate learners about the disadvantages of falling pregnant whilst at school. The risk of infected by sexual transmitted diseases, difficulties in maintaining and supporting the baby, the risk of leaving school and ending their careers for good and jeopardizing their opportunities for possible future marriage might be overwhelming. Social workers are sometimes invited to address this problem. The sixth respondent pointed out that parents of the learner should be invited and advised to give a full support to the child related to medical care and advice from the health officials. During examinations, parents or guardian are to at school on a standby duty in case a learner gets sick. In times of emergency, we call medical practitioners. The seventh respondent indicated that according to the law, no child should be denied the right to education because of pregnancy. Therefore, the child cannot be expelled. The only way to manage this problem is by having regular meeting with the learner to find out the state of the pregnancy. The principal should always update the SGB on the problem. The eighth respondent showed that the parents of the learner should take full responsibility on the medical care of the learner. One of the parents should accompany the learner to school every day more especially during examination. The ninth respondent indicated that sex education is essential in dealing with teenage pregnancy. The counselling of female learners should be 
done more often in schools. It is the principal's responsibility to consult the parents of the learners to ensure stable relationship and conducive environment for both mother and the baby. The principal should involve authority figures including supervisors, human resource staff and School Governing Body. The tenth respondent indicated that the principal should call the psychologists, nurses and social workers to conduct an awareness campaign in order to empower teenage girls about the danger of teenage pregnancy to their health and academic performance. Dramas and essays will be conducted so that learners' knowledge about teenage pregnancy could be enhanced.

The responses of the respondents to the interview question showed that the respondents know and understand the danger of using General knowledge in this regard because parents are aware of the right to education by their children. The principals have no right to expel the learner due to teenage pregnancy, the principal still have responsibility to ensure the safety of the learner and her baby. Although the respondents appeared not to have an in-depth-knowledge of the Policy related to teenage pregnancy. They appeared to have no clear policy in their schools related to teenage pregnancy hence they have knowledge about the Constitution of the country and South African School Act. The School Policy could assist them to apply Specific Knowledge to the occurrence of this nature.

\section{How do you deal with bulling cases in your school?}

The first respondent pointed out that if teachers could always be in classes, this bulling can be addressed easily and speedily. Labeling of learners is strictly prohibited in a school, setting of clear and enforceable of rules and expectations help in dealing with bulling cases. The second respondent indicated that parents must be engaged in all school matters so that the school could get support in the fight against bulling cases. Parents should be asked to disclose the behavior of their children so that school could keep an eye to the learner of unacceptable behavior. The third respondent showed that the school should enforce all rules and regulations related to bulling as part of code of conduct of learners. Any bulling including minor or severe bulling should be treated vigorously and rigorously. School conference day should be adopted to focus on issues including bulling and others. The fourth respondent indicated that parents should be advised to monitor school surroundings during school hours and after school hours. Communication amongst school administrators, teachers, parents and learners should improve. The school should have a school problem box where learners can report problems including bulling. Learners should be encouraged to tell one another if they happen to experience such a problem. The fifth respondent pointed out that bulling is a serious offence in schools. To handle this problem satisfactorily, you have to get stories from both sides including the perpetrator and the victim. The perpetrator should know the consequences of offence during the discussions. Both of them should sign in the record of misconduct. If the same bulling continues, this should be brought to the attention of both parents and the SGB. The sixth respondent showed that one should choose 
the right time and place to resolve conflict as soon as possible. Don't tackle this problem in front of the group and always stay calm to control your emotions. Listen to both sides of the story from the affected individuals without taking sides. This can be done on one to one basis or together depending on the situation on hand. Thereafter, look for possible solutions. The seventh respondent showed that when dealing with bulling case documentation should be taken into consideration for references. Listen attentively and demonstrate empathy to the victim, when asking questions to probe the issue, focus on the problem but not the person. Take a collaborative and creative approach focused on problem-solving and not blaming someone. Let them come with the best solution and agree with them. Don't assume that a conflict is resolved after discussions, make a follow up to determine if the solution is working or not. The eighth respondent indicated that prevention is better than cure in this regard. One should always talk about bulling with learners to avoid acts of bulling in school. Encourage learners to speak out if such incidence happens. If it happens, the investigation should be conducted and documented for references. Both parents should be informed about the incidence so that they could also contribute towards the solution. If the perpetrator pleads guilty, we give a punishment. We also counsel them all including both victim and perpetrator. The ninth respondent indicated that an anti-bulling campaign should be established in the school to fight against this problem. This should be regulations in each school to control bulling which should be included in the code of conduct. When this problem happens, we involve other stakeholders such as counsellors and psychologists for assistance. The tenth respondent pointed that policing forum, community structures and Non-Governmental Organization play vital role in the fight against bulling in schools. Therefore, schools should operate in partnership this structure for bulling free school. Learners Representative Committee should also be empowered to assist School Management Team in the fight against bulling in school.

The responses to the interview question showed that the respondents are crystal clear that bulling should be dealt with, with care because one could worsen the problem. The leadership should by all means try to find out the contributing factor of each case by listening to both affected learners. The campaign of free school bulling should be done including different stakeholders such as parents, Community Policing Forum, counselors, psychologists and other Non-Governmental Organizations. The school leadership should document each case and its resolution for reference. The respondents are quite certain that their decision -making process should never be facilitated by their emotions. Therefore, they appeared to agree that General Knowledge is not employable towards the solution of this problem.

What procedures would you prefer to solve educators' conflict?

The first respondent indicated that the best way to solve the conflict you have to get stories from both parties and you do not have to give judgment. They 
people affected should come up with resolution to show amicable agreement. All affected should consider the interest in the resolution they adhere to. The second respondent showed that you have to start by identifying the problem and get both sides of the story. After that, you have to analyze them in order to identify points of agreement and disagreement. Thereafter, you prioritize areas of conflict. Again you have to develop a plan of action that could accommodate both parties. Emphasize the need to build and work on their relationship. The third respondent pointed out that you have start by identify the problem and then invite them all. If the conflict grows, the School Management Team could be involved towards the solution to the problem. To promote unity, the syndicate and stokvel should be introduced in schools so that they will be always together more especially during breaks. The fourth respondent indicated that you have to choose the right time and place to resolve conflict as soon as possible. Do not tackle the issue in front of the group and always stay calm and control your emotions. You have to listen to both sides of the story from the affected individuals without taking side. Thereafter you have to look for possible solutions. The fifth respondent pointed out that you have to get a full story before you adjudicate the case. All the meetings with affected individuals should be recorded for future reference. Listen actively to both parties with sympathy, and when you ask questions, focus on the problem and nothing else. You have to get the policy document when dealing with such a problem. Take a collaborative approach that focus on problem-solving and do not blame any of them. They have come with solution to the problem themselves. You have to make sure that they affected individual could start working together harmoniously. The sixth respondent showed that you have to workshop your teachers before the problem emanate so that they know the code of conduct in terms of Employment of Educators Act and South African Council of Educators (SACE). If it happens, your role is to find out what the problem is and its cause. You have to use a win-win approach as much as possible. The seventh respondent indicated that you have identified the cause of the problem and try to get the background to the problem. Then, try to get strategies to unite different groups. Discuss the problem with the idea of solving it, but not with the idea of wining the argument. Avoid making personal attack. The eighth respondent pointed out that all parties should be invited for engagement with amicable solutions. The problems should be addressed with good ideas of finding the solution to the problem. You have to guide the discussions towards the solutions to the problem. Reprimand one who tries to direct argument at a person. The ninth respondent indicated that educators are professionals by nature and conduct. Both parties should be interviewed in order to give advice and guidance. The affected individuals should be told that a school is not a battleground for educators but a learning and teaching place. The tenth respondent showed that when educators are in differences, you have to bring policy document to them. Give them chance to read on the behavior of an educator. After that discuss the problem with the educator's code of conduct in 
mind, the affected educators should come with the solution to the problem themselves.

The responses to the research question, showed that the respondents do not want to rely on the General knowledge when dealing with the conflict amongst educators themselves. They believe that the solution to any problem which has to do misunderstanding amongst themselves lies in educators affected by the problem. The school leadership has to listen both parties affected and facilitate discussions to amicable and harmonious solution. The whole process of resolving conflict should be based on the School Policy, Educators Employment Act and South African Council of Educators. It is crystal clear that the respondents are aware that they should be guided by the documents to use Specific Knowledge instead of General Knowledge. They understand this democratic culture.

\section{Discussions}

The specific knowledge stored and used in an exceptional attribute in the functioning and it is a specific combination of ideas, institutions, the experience and the skills of people and their teams or group and the skills of people and their teams or group. It is often reflected both in documents and in the processes and procedures, practices and norms of the organization, and in the followed customs. Knowledge gives an ability to solve problems on the basis of the possessed information and the added value resulting from specific knowledge (Borowiecki \& Siuta-Tokarska, 2013). For this study, the leadership more especially principals of schools should design policy when they want to introduce whatever at their work environment to meet any challenge that may arise. They policy should be a written document which is accessible to whoever would like to have knowledge about that policy. This would assist principal of schools to employ specific knowledge to whatever challenge they would happen to deal with. Turning policy into delivery is one of the attributes of effective leadership. However, turning policy into delivery is not a simplistic issue. It is the leadership's obligation to understand the policy to enhance their knowledge.

The possibility of designing proper methods and tools to facilitate effect knowledge transfer between individuals and organizations, to allow storage of knowledge inn some kind of repository and to facilitate and reuse of knowledge requires as a definition of knowledge which must be, at the same time, conceptually sound and application to practical purposes (Bolisani, Borgo, \& Oltramari, 2017). The policy will have to include mechanics of intelligence as well as the pragmatics of intelligence. All these would assist towards mitigating both educational and political naivety at a work environment.

Although other people see as a burden to have organizational knowledge it is imperative to have that specific knowledge. To get specific knowledge appears to be time consuming to most of the people. The employees have to struggle to find the right information in the midst of the information noise to help them to meet challenges. The management is key position in a knowledge sharing program. 
Knowledge sharing is about taking the knowledge of an individual and transforming it into organizational knowledge (Heinila, 2019). It is crucial to have organizational knowledge to help you to give adequate responses to any challenge at the work environment. The leadership should have clear knowledge about their subordinates to guarantee the quality at the work environment.

Aven (2017) highlights that the general knowledge is learned in a structured setting, is controlled by a large number of people with general knowledge. This type of knowledge can be transferred easily across individuals and provides the basis for the decisions at the early stages of a development project or management. Ravikant (2019) states that specific knowledge is also known as idiosyncratic knowledge and is possessed by a few number of individuals since it is expensive and difficult to transfer. Aven (2017) notes that specific knowledge is not learned but one gets this knowledge through working with experienced person in a particular field. This shows that for one to become a school manager, experience in management is required. For this study, it appears that there is an increasing awareness and recognition of the lack of knowledge in relation to the understanding of management issues by school managers. The schools are confronted with risk taking or management challenging issues, hence there is a need for the school managers to understand the general and the specific knowledge.

Ravikant (2019) explains that the specific knowledge is technical and creative which permits the school managers to have social skills that are developed through interacting with people by observing, listening and speaking to people. The specific knowledge becomes important in making decisions, which is the operational stage. The school managers possess skills which they combine them with the past experiences when deciding or responding in a particular situation and is achieved through trial and error method or through practicing. Kaya and Seleti (2013) reveal the wealth of knowledge that still exists among the elders and knowledge holders which demonstrate the crucial role played by past experience in managing situations.

Correspondingly, Aven and Kristensen (2019) note that the dialogue and discursive strategies are relevant in deliberations as a way of solving management issues. The specific knowledge assists the school managers to solve problems in different situations they encounter in management. However, Soudien (2015) in the study conducted in Cape Town notes that South Africa becomes trapped since it lacks the intervention strategies when it comes to problem solving of school management issues. Also, Kaya and Seleti (2013) note that the education system in South Africa has its own challenges which are a result of lack of a holistic, community based nature approach and knowledge production specific to institutional management. Likewise, Soudien (2015) highlights that South Africa needs managers with new ideas of scientific management, knowledge driven administration and expertise-led policy making. Kaya and Seleti (2013) highlight the relevance of integrating both the general and specific knowledge in solving school related issues which will provide relevance and management of education 
by providing an education that adheres to their own inherent perspectives, experiences, language. Of importance is to note that for the school managers to find solutions in their schools, action in making relevant decision and accountability lead to the solution in challenges within the schools.

\section{Conclusion}

The responses to the interview questions pointed out that the respondents are crystal clear that in the democratic culture, general knowledge should not be employed to resolve any problem. The leadership should have in-depth knowledge of their institution to avoid the use of general knowledge because in all work environments, the subordinates of leadership are abreast of the working conditions. Therefore, the respondents showed that whatever the leadership implement should be grounded by the policy that will be a clear evidence of specific knowledge. In all schools, there should be Teaching and Learning Policy to ensure quality teaching. It is advisable that whatever they think could contribute significantly towards ensuring quality teaching and should be included in the policy to avoid naive arguments. Again, they are aware that corporal punishment is a serious misconduct by whoever inflicted it. They confirmed that nobody should use general knowledge to resolve any problem that deserves punishment but School Policy should have a clear cut on the misconduct by the learner to avoid the implementation of corporal punishment which is the subsequent of general knowledge. The code of conduct in the School Policy should include the misconduct by the educator. To avoid the implementation of general knowledge in all institution, a clear and comprehensive policy should be designed. The leadership should vigorously and rigorously implement the School Policy because both parents and learners are abreast of this democratic culture. This could hamper naïve argument and promote intellectual argument that could amplify competence in the work environment. Over and above, Continuing Professional Education could enhance the leadership knowledge and skills by such a profound understanding. However, specific knowledge should also be implemented by all people who make up that institution to meet and respond to all challenges.

\section{Conflicts of Interest}

The authors declare no conflicts of interest regarding the publication of this paper.

\section{References}

Aven, T. (2017). Improving Risk Characterizations in Practical Situations by Highlighting Knowledge Aspects with Applications to Risk Matrices. Reliability Engineering \& System Safety, 167, 42-48.

Aven, T., \& Kristensen, V. (2019). How the Distinction between General Knowledge and Specific Knowledge Can Improve the Foundation and Practice of Risk Assessment and Risk-Informed Decision-Making. Reliability Engineering \& System Safety, 191. 
Bolisani, E., Borgo, S., \& Oltramari, A. (2017). Using Knowledge as an Object: Challenges and Implications. Knowledge Management Research \& Practice, 10, 202-205.

https://doi.org/10.1057/kmrp.2012.32

Borowiecki, R., \& Siuta-Tokarska, B. (2013). Challenges and Problems of Knowledge Management in Enterprises in Poland. China-USA Business Review, 12, 149-162. https://doi.org/10.17265/1537-1514/2013.02.006

Furnham, A., \& Premuzic, T. C. (2006). Personality. Intelligence and General Knowledge. Learning and Individual Differences, 16, 79-90.

Heinila, R. (2019). Organizational Knowledge: Challenges and Best Practices. Smarp.

Hossain, M. Z., \& Mozumder, M. A. K. (2019). Prospects of Principal Leadership in Schools and Colleges in Bangladesh. Open Journal of Social Sciences, 7, 44-50. https://doi.org/10.4236/jss.2019.79004

Hrdy, C. A. (2019). Boston College Law Review.

Indeed Editorial Team (2020). Problem-Solving Skills, Definitions and Examples. Indeed.com.

Kaya, H. O., \& Seleti, Y. N. (2013). African Indigenous Knowledge Systems and Relevance to Higher Education in South Africa. The International Journal: Comparative Perspective, 12, 30-44.

Kozminsky, E. (2001). How Do General Knowledge and Reading Strategies Ability Relate to Reading Comprehension of High School Students at Different Educational Levels? Journal of Research in Reading, 24, 187-204. https://doi.org/10.1111/1467-9817.00141

Ravikant, N. (2019). Specific Knowledge Is Highly Creative or Technical. https://nav.al/Creative-technical

Soudien, C. (2015). Curriculum, Knowledge and Idea of South Africa. Cape Town: University of Cape Town.

Waschenfelders, T. (2019). Apply Specific Knowledge: Technikon and Creative Knowledge on the Edge of Your Field. Home Articles Newsletter. 